\title{
PLASTRAL RESPIRATORY DEVICES IN ADULT CRYPHOCRICOS (NAUCORIDAE: HETEROPTERA)*
}

\author{
By Margaret C. Parsons and Rosemary J. Hewson \\ Department of Zoology \\ University of Toronto \\ Toronto, Ontario $\mathrm{M}_{5} \mathrm{~S}_{1} \mathrm{~A}_{\mathrm{I}}$
}

\section{INTRODUCTION}

Adult Cryphocricos live in very rapid, well-aerated streams, under stones and gravel at depths of from 6 to 24 inches (Fritz Plaumann, personal communication; John Polhemus, personal communication; Randall Schuh, personal communication). Under these conditions it would be difficult for these insects to come to the water surface for atmospheric air, as do "slow-water" Naucoridae and most other aquatic Heteroptera, and neither Polhemus (personal communication) nor Schuh (personal communication) have observed them to do so.

Even if it were possible for Cryphocricos to obtain atmospheric air, the insects lack a means of storing large amounts of it for underwater respiration. Aquatic Heteroptera with "air-bubble" respiration carry much atmospheric air under their long forewings and trapped by long hairs on the ventral surfaces of their bodies. Long-winged Cryphocricos, however, are very rare. Most individuals lack hindwings and have forewings which reach only to the third abdominal segment. The reduced subalar space on the pterothorax is too small to hold any appreciable amount of air (Parsons 1974). Thorpe (1950) concluded, from examination of a dried specimen of Cryphocricos sp., that it is "a bubble-carrier rather than a true plastron insect" and has "a substantial air film". Polhemus, however, examined $C$. hungerfordi in the field and observed no such air layer except on the six pairs of small ventral abdominal sense organs (Polhemus, personal communication). Parsons (1974) observed a very thin air layer on the ventral surfaces of the thorax and abdomen in formalinpreserved $C$. barozzii, but this layer is visible only under the stereoscopic microscope and is usually hidden by the debris which covers the insect.

Young's (1944) suggestion that Cheirochela (Naucoridae) survives by cutaneous respiration appears highly dubious, and it is unlikely that Cryphocricos uses this method to any great extent. The

*Manuscript received by the editor February 6, 1975 
exoskeleton is quite thick, and the relatively large size of the insect (C. hungerfordi is 8.5-9.5 mm long; $C$. barozzii is IO- $13 \mathrm{~mm}$ long) produces an unfavorable ratio of volume to surface area.

Among the aquatic Heteroptera, true plastral respiration has thus far been experimentally demonstrated only in Aphelocheirus (Thorpe and Crisp 1947a, 1947b; Thorpe 1950). Whether this insect is a naucorid (Usinger 1956) or represents a separate family, the Aphelocheiridae (Parsons 1969) is debatable. Aphelocheirus possesses a very thin, permanent air layer, or "plastron", which is retained by short, densely-packed hairs on most of the dorsal and ventral surfaces of the body. The plastron is exposed to the water and acts as a gill, obtaining enough dissolved oxygen from the water to make the insect independent of atmospheric oxygen (Thorpe and Crisp 1947a; Thorpe 1950). Cryphocricos and Aphelocheirus share such morphological similarities as reduced forewings, vestigial hindwings, lack of a large air store, and paired abdominal pressure receptors of a type not yet reported in any other Heteroptera (Aphelocheirus, Thorpe and Crisp 1947c, Larsén 1955; Cryphocricos, Thorpe 1950, Parsons 1974). These similarities suggest that Cryphocricos, like Aphelocheirus, has a plastral type of respiration. Hinton (1969a, p. 198) has remarked that "Por ejemplo, entre insectos adultos hay por lo menos cuatro orígenes independientes de respiración de plastrón dentro de la familia Naucoridae: Aphelocheirus, Cryphocricos, Heleocoris, e Idiocarus". He included a photomicrograph of thoracic plastral hairs in Heleocoris but did not further elaborate on his statement.

Although the presence of plastral respiration would be best demonstrated by both morphological and physiological studies, live specimens of Cryphocricos were not available for experimentation. Our investigation, like Hinton's (1969b) study on aquatic beetles, was therefore confined to morphology. Its purposes were (I) to discover whether the exposed surfaces of the body possess hydrofuge devices which might retain a thin plastral air layer, and (2) briefly to compare any such structures with those of other insects in which plastral respiration is believed to occur.

\section{Materials and Methods}

Species used:

Cryphocricos barozzii Signoret (preserved in formalin; collected in Brazil by F. Plaumann; two specimens)

C. hungerfordi Usinger (preserved in alcohol; collected in Mexico by J. T. Polhemus; one specimen) 
Aphelocheirus aestivalis Fabricius (preserved in Bouin's fluid; collected in England by D. T. Crisp; two specimens)

The specimens were first dissected in $80 \%$ alcohol under a stereoscopic microscope. They were cut midsagittally with a razor blade and the ventral and dorsal surfaces of one or both halves were separated along the lateral edge. On one specimen of Aphelocheirus a small section of the metathoracic episternum was removed so that the cut edge could be examined. A major obstacle was the presence of large amounts of silt and other debris on the external surfaces of all three species. Treatment with weak solutions of either potassium hydroxide or Sparkleen detergent failed to remove it. Somewhat better results were obtained by scraping small areas with watchmaker's forceps.

The specimens were then mounted with double-sided tape on aluminum stubs, freeze-dried, and coated, in an Edwards vacuum evaporator, Model 4, with a layer of gold which was approximately 200-400 A thick. They were examined in a Cambridge Stereoscan, Model 2A, and photographed with a Singer camera, using Ilford 120 roll film.

\section{ObServations}

Ventral Surface

(I) Plastral Hairs

In both species of Cryphocricos most of the ventral surface is covered with densely-packed hairs (Fig. 3). They occur on the pro-

Fig. 1. Cryphocricos barozzii; ventral view, legs removed. Stippling on fourth through sixth abdominal sternites indicates area of microtrichia (Fig. 11) ; stippling on ventral abdominal paratergites, left side of figure, indicates area of short leaf-like setae (Figs. 6-8). Longer leaf-like setae occur on the six pairs of abdominal sense organs. Most of the ventral surface is covered with plastral hairs (Figs. 3, 4).

Abbreviations: EM, epimeron; ES, episternum; FW, forewing; LS, longitudinal sulcus; MCI, metacoxal indentation on abdomen; PT, ventral abdominal paratergite; SO, abdominal sense organ; SP, abdominal spiracle; ST, sternite. Arabic numerals indicate abdominal segments; Roman numerals indicate thoracic segments.

Fig. 2. Cryphocricos barozzii; dorsal view, right forewing removed, revealing smooth subalar surfaces on right side (even stippling). Other surfaces are roughened. For distribution of plastral hairs, see text.

Abbreviations: TI, TII, TIII, thoracic terga; T1, T2, T3, abdominal terga. 
1974] Parsons \& Hewson - Cryphocricos
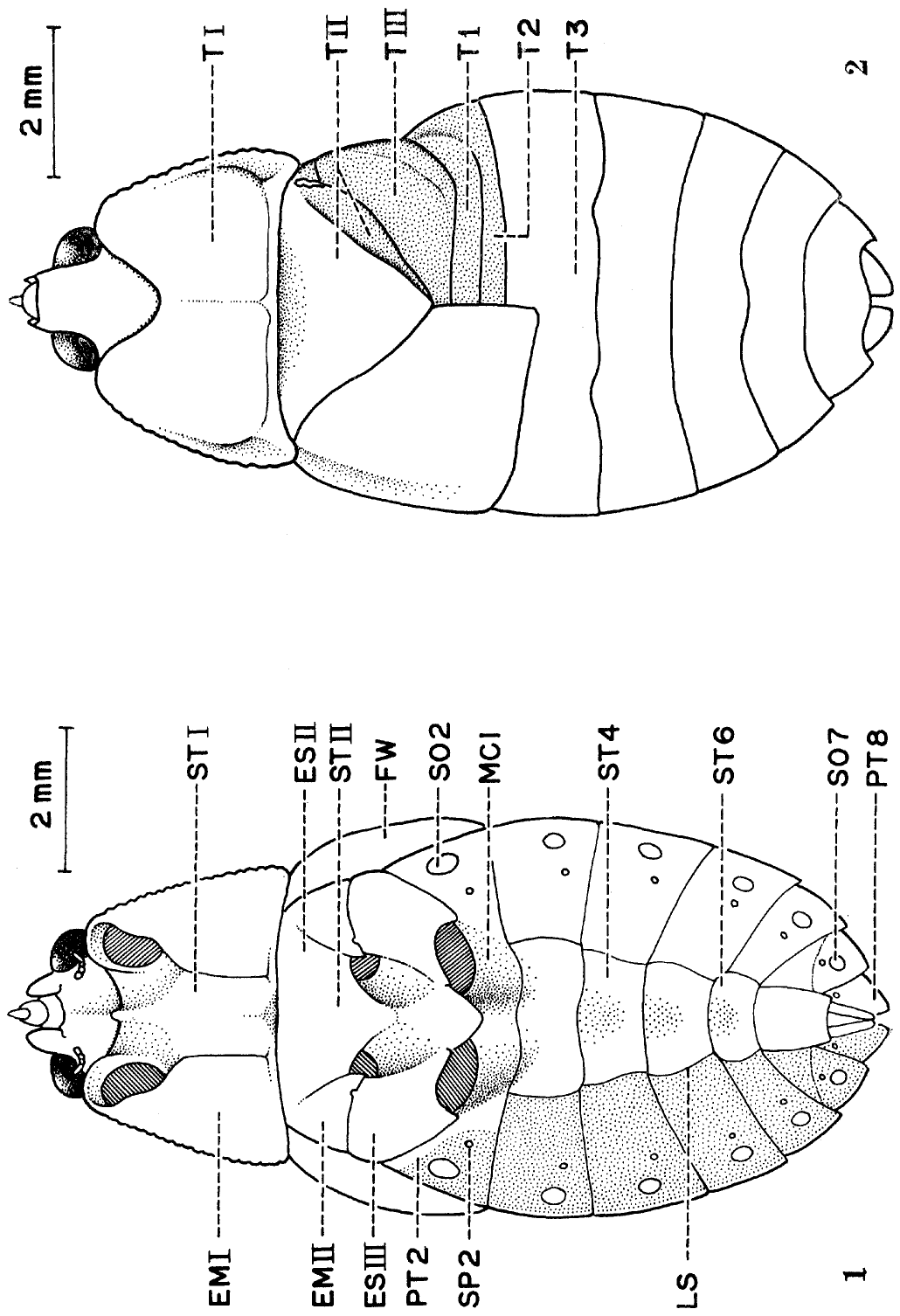
thoracic epimeron and sternum (Fig. I, EM I, ST I), the mesothoracic epimeron, episternum, and sternum (EM II, ES II, ST II), the metathoracic episternum (ES III), and all seven ventral abdominal paratergites (PT 2-PT 8). They also cover all of the third and seventh abdominal sternites and all but the anteromedial portions of the fourth through sixth sternites (ST 4-ST 6).

The close spacing of the hairs makes it difficult to see their bases and to measure their length. Their visible portions are at least $6 \mu \mathrm{m}$ long and from 0.25 to $0.45 \mu \mathrm{m}$ in diameter on the thorax and paratergites (Fig. 4). They are considerably shorter and wider on the abdominal sternites; on a sagittal cut through the fifth sternite, where the entire length of a few hairs was visible, they were only $2.7 \mu \mathrm{m}$ long but $0.65 \mu \mathrm{m}$ in diameter.

Comparison of the thoracic and paratergal hairs with the plastral hairs of Aphelocheirus (Fig. 5) shows similarities which strongly suggest that those of Cryphocricos (Fig. 4) are also plastral devices. The most striking similarities are (I) the presence of small nodules on the basal portions of the hairs, (2) the densely-packed arrangement of these hairs, and (3) the posterior bending of their apical portions, which lack nodules. Using the light microscope and transmission electron microscope, Thorpe and Crisp ( I947a) observed the bending of the hairs in Aphelocheirus but did not see the nodules. The bending appears to be more pronounced in both specimens of Aphelocheirus than in the three specimens of Cryphocricos. In both genera the hairs tend to adhere to each other in clumps, making the direction of the bending difficult to detect in surface view (Fig. 3); the clumping is probably an artifact.

Fig. 3. Cryphocricos barozzii; surface view of apical parts of plastral hairs on metathoracic episternum. More basal parts of hairs, with nodules, visible at lower left. Clumping of tips is probably an artifact. Left $=$ posterior, right $=$ anterior. Scale line $=2 \mu \mathrm{m}$.

Fig. 4. C. barozzii; clump of plastral hairs on fifth ventral abdominal paratergite. Leaf-like setae, which concealed these hairs, were scraped off during preparation of specimen. Bases of hairs were concealed by tips of surrounding hairs. Note posterior (to right) bending of apices and presence of nodules on proximal parts of hairs. Scale line $=1 \mu \mathrm{m}$.

Fig. 5. Aphelocheirus aestivalis; cut edge of metathoracic episternum, showing full length of plastral hairs. Note posterior (to right) bending of apices and presence of basal nodules. Scale line $=1 \mu \mathrm{m}$. 


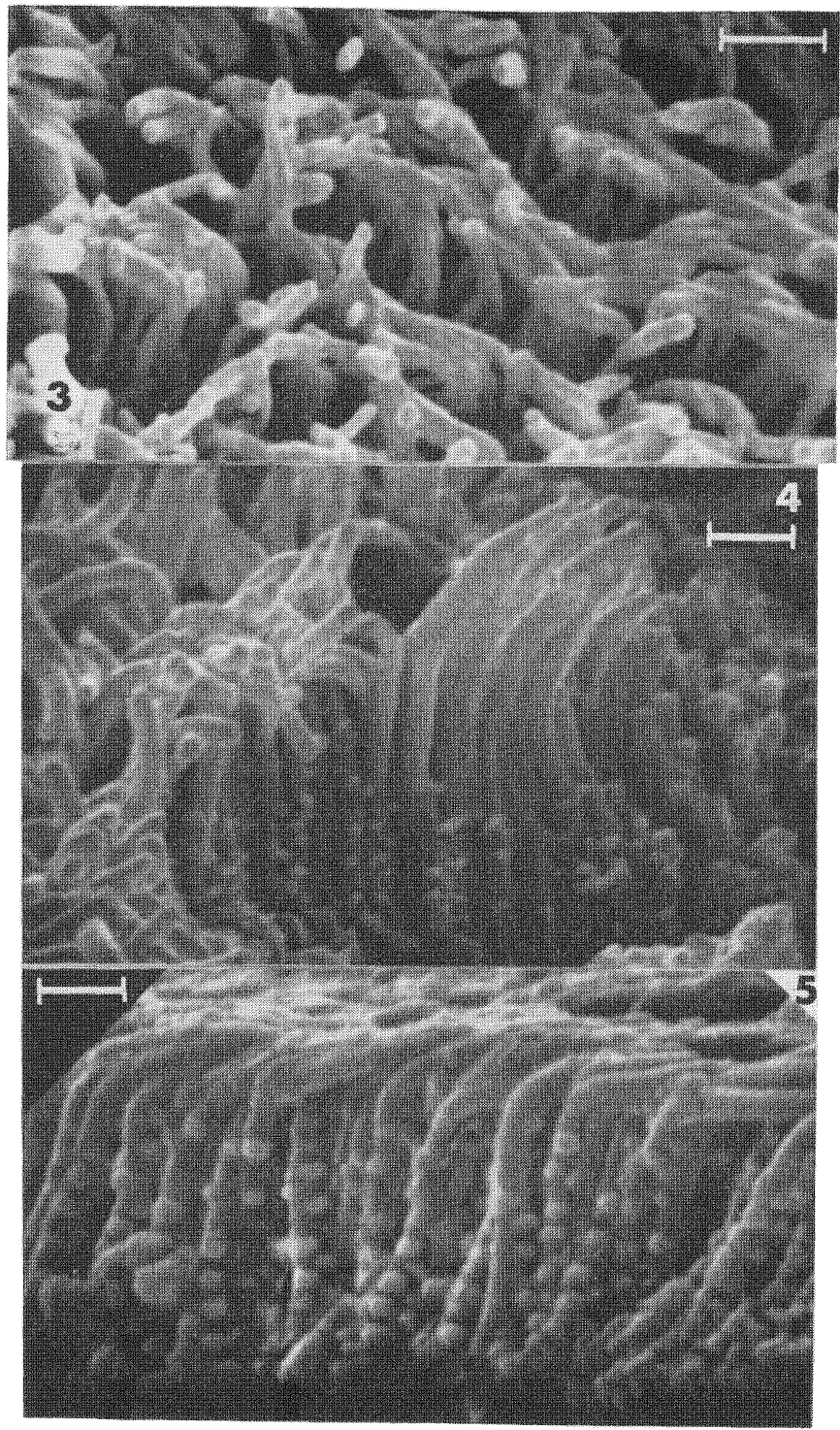


The thoracic plastral hairs of Aphelocheirus are approximately 5-6 $\mu \mathrm{m}$ in length, as Thorpe (1950) also noted. They are thus somewhat shorter than those of Cryphocricos, but appear to be comparable to the latter in diameter. Their bases are somewhat thicker (approximately $0.4 \mu \mathrm{m}$ ) than their tips (approximately $0.3-0.35 \mu \mathrm{m}$ ). In both genera adjacent hairs seem to lie very close to each other. The nodules may help to hold them apart, allowing room for air to circulate between them. Also, because of the thickness of the gold coating $(0.02-0.04 \mu \mathrm{m})$, the hairs probably appear, under the scanning electron microscope, somewhat thicker, and the intervening spaces smaller, than they actually are. By means of the light and transmission electron microscopes, Thorpe and Crisp (1947a) estimated the space between adiacent hairs on the abdominal sternites of Aphelocheirus to be approximately twice as great $(0.4 \mu \mathrm{m})$ as the diameter of the tip of a single hair $(0.18-\cap .25 \mu \mathrm{m})$. The discrepancy between their observations and ours may be due, in part, to the different techniques employed. It is also possible that the hairs are less densely packed on the abdominal sternites than on the thorax of Aphelocheirus.

The hairs of both Cryphocricos and Aphelocheirus are much shorter, narrower, and more densely packed than those which cover the ventral surface of the abdomen of Pelocoris femoratus, a "slowwater" naucorid with air-bubble respiration (Parsons 1974). A brief observation of one specimen of Pelocoris revealed that the hairs on the second abdominal paratergite lack basal nodules and are 30-4O $\mu \mathrm{m}$ long, $2-3 \mu \mathrm{m}$ wide at the base, and approximately Io $\mu \mathrm{m}$ apart.

\section{(2) Leaf-like Setae}

Leaf-like setae occur on the ventral paratergites of the abdomen (Fig. I, light stippling lateral to LS). They extend all the way to the lateral edge of the body on the second abdominal paratergite, and nearly to the lateral edge on the more posterior paratergites. On the second paratergite (PT 2) a narrow anteromedial strip adjoining the metathoracic episternum (ES III) and the metacoxal indentation (MCI) lacks leaf-like setae (Fig. 6). This "nonfoliated" region is larger in Cryphocricos hungerfordi than in C. barozzii. The second abdominal spiracle (Fig. I, SP 2) and sense organ ( $\mathrm{SO}_{2}$ ), like those of the other abdominal segments, lie in the "foliated" region.

In $C$. barozzii the flattened setae are widest $(8-20 \mu \mathrm{m})$ near their bases and are $20-40 \mu \mathrm{m}$ long. In $C$. hungerfordi, a smaller insect, they are approximately $75 \%$ this size. They appear to be socketed (Fig. 8) and are arranged somewhat like shingles, in closely packed, 

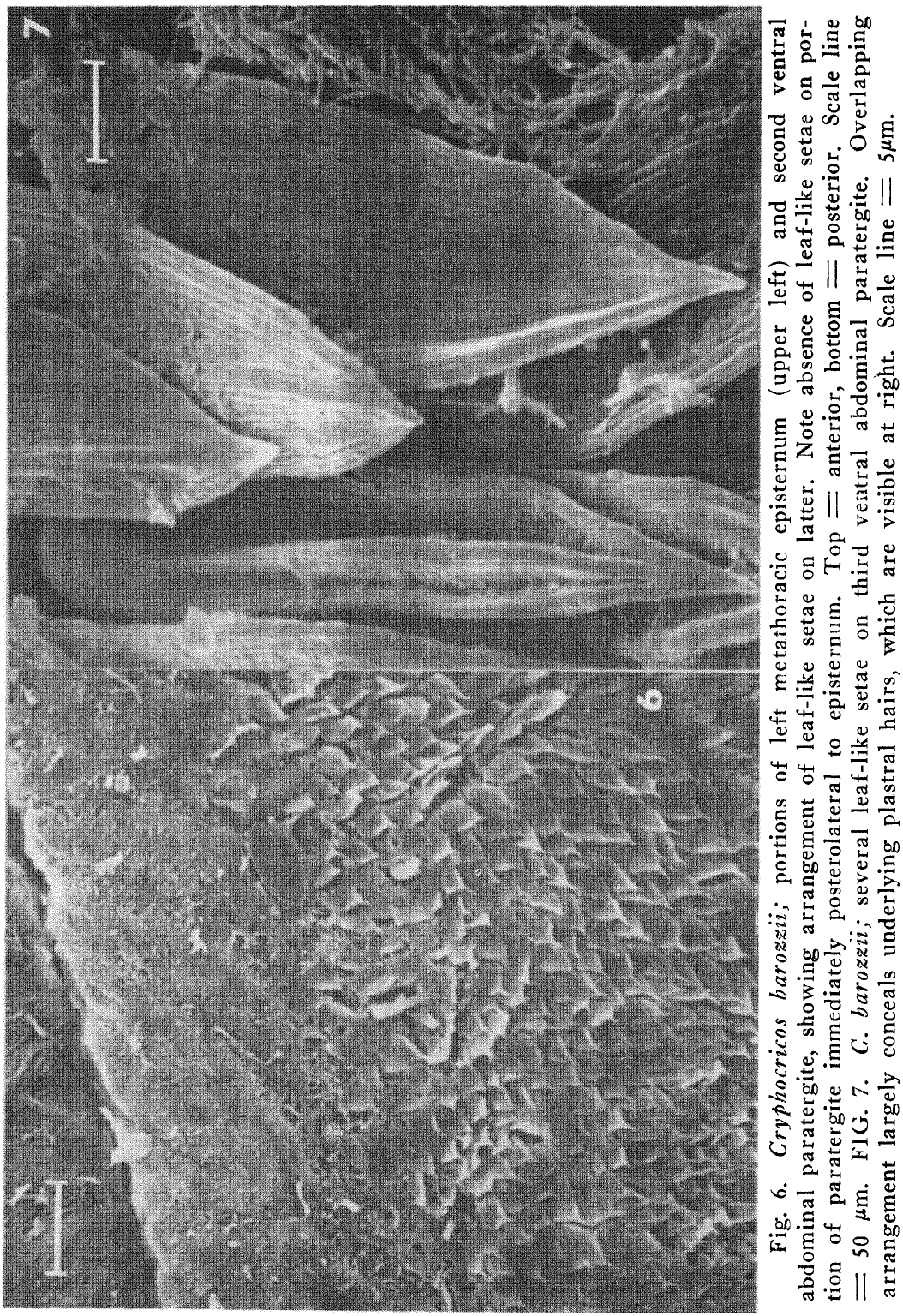
somewhat irregular rows, each row overlapping the one posterior to it (Figs. 6, 7). The tapered tip of each seta points posteriorly and somewhat laterally on the body except in the spiracular regions, where those immediately lateral to the spiracles point posteromedially. On the eighth paratergite the setae are fewer and farther apart and do not overlap.

Under the stereoscopic microscope the ventral paratergites, unlike the "nonfoliated" regions of the body, have a faintly golden sheen. The sheen is visible when specimens are immersed in alcohol, which would remove any adherent air layer. It is probably the result of light diffraction by the fine longitudinal ridges on the ventral surfaces of the flattened setae (Figs. 7, 8).

In their shape and overlapping arrangement the setae resemble the plastral devices of Phytobius (Coleoptera; Thorpe and Crisp 1949). Unlike the latter, however, they do not bear plastral hairs on their external surfaces. The plastral hairs arise from the exoskeletal surface beneath the leaf-like setae and are largely concealed by them (Fig. 7) but were clearly visible in regions where the setae had been scraped off with watchmaker's forceps (Fig. 4). Although the setae do not completely cover the ventral abdominal spiracles they overlap so much of their margins that we could not observe spiracular structure or determine whether or not they possess radiating "rosettes" similar to those of the second through seventh abdominal spiracles of Aphelocheirus (Thorpe and Crisp 1947a).

The second through seventh abdominal sense organs (Fig. I, SO 2SO 7) are composed of leaf-like setae which are two to three times longer than those covering the rest of each paratergite (Fig. 9). Most of these elongated setae project more laterally than the shorter ones, and have blunter tips and more pronounced longitudinal ridges

Fig. 8. Cryphocricos hungerfordi; detail of one leaf-like seta on fifth ventral abdominal paratergite. Note longitudinal ridges and tapering tip, which points posterolaterally (lower left). Surrounding setae were rubbed off, revealing tips of underlying plastral hairs and apparently socketed base of seta. Scale line $=2 \mu \mathrm{m}$.

Fig. 9. C. barozzii; sense organ on third ventral abdominal paratergite Sense organ is composed of elongated leaf-like setae. Tips of shorter leaf-like setae, covering rest of paratergite, are visible at bottom and upper left of figure. Right $=$ lateral, bottom $=$ posterior. Scale line $=$ $30 \mu \mathrm{m}$.

Fig. 10. C. barozzii; detail of Fig. 9, showing longitudinal ridges on elongated leaf-like setae. Scale line $=2 \mu \mathrm{m}$. 


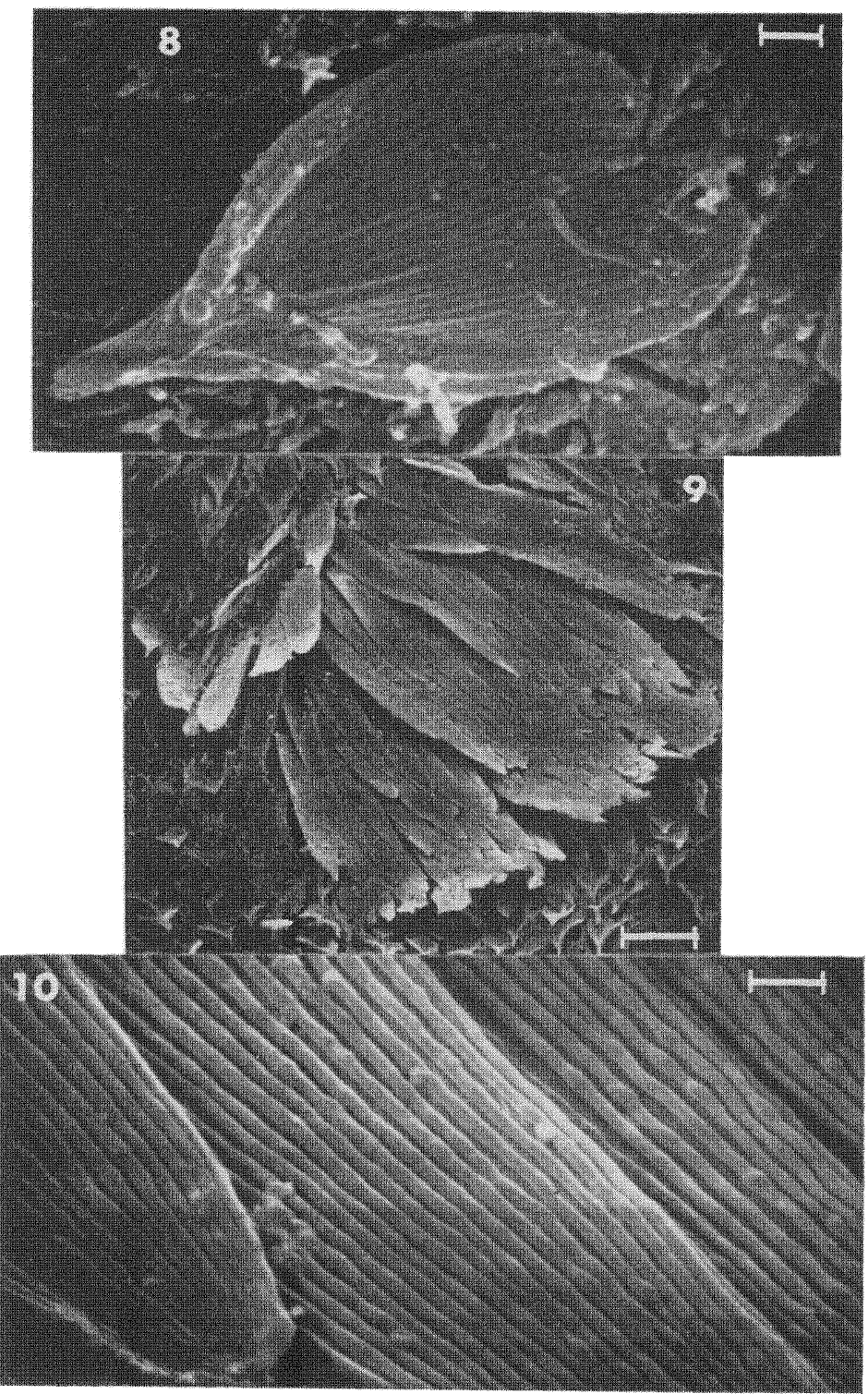


(Fig. IO). A considerable quantity of air is trapped among these overlapping, elongated setae. On living specimens the sense organs are the only parts of the body on which air can be seen with the naked eye (Polhemus, personal communication), and the air on these regions is easily seen with the stereoscopic microscope.

In Aphelocheirus similar sense organs, which are probably pressure receptors, occur only on the second abdominal segment (Thorpe and Crisp 1947c). Like those of Cryphocricos they are composed of flattened, elongated setae, approximately $75 \mu \mathrm{m}$ long, which point posterolaterally and overlap each other. The setae appear to be longitudinally ridged, although this could not be determined with certainty because of the large amount of debris which covered them. Leaf-like setae were not observed on any other region of the body of Aphelocheirus.

\section{(3) Microtrichia}

On the anteriormost portions of the fourth through sixth abdominal sternites (Fig. I, ST 4-ST 6) plastral hairs occur only laterally; near the midline they are lacking. The only structures observed in this hairless region are short, blunt microtrichia, approximately I $\mu \mathrm{m}$ wide at the bases and $2 \mu \mathrm{m}$ long, which project posteriorly. They are arranged in widely-spaced groups of from two to six. Each group of microtrichia arises from the slightly raised, curved, posterior edge of a roughly semicircular region of the cuticle. The microtrichia lack sockets and lie nearly parallel to the surface of the cuticle.

More posteriorly on the fourth through sixth sternites, but not as far as the posteriormost edge, the microtrichia are more numerous per group, longer (up to $3 \mu \mathrm{m}$ ), and occur in more closely-spaced groups (Fig. II). Each group consists of 5-15 microtrichia and these, along with the region of smooth cuticle to which they attach, form a fringed, semicircular unit. The units are arranged like shingles. On this central part of the sternite, unlike the more anterior region, hairs appear to be present between adjacent rows of microtrichia. Since only the tips of these hairs are visible, we could not determine whether they are similar to the short plastral hairs which cover the lateral and posterior regions of the fourth through sixth sternites; these regions lack microtrichia (Fig. I, unstippled portions of ST ${ }_{4}-\mathrm{ST} 6$ ).

(4) Fringed Setae (Fig. I2)

Fringed setae may occur either singly or in large numbers. They arise from sockets in the cuticle and project posterolaterally. A trans- 
verse section through a fringed seta near its base would appear as a nearly complete circle, with the open end facing away from the cuticle. Towards the tips the setae are wider, more flattened, and would appear as more widely open arcs in transverse section. Their outer surfaces bear longitudinal grooves corresponding to pronounced ridges on their inner surfaces. The apical portion of each of these ridges subdivides into several short projections which give the seta a fringed appearance. The sizes of the fringed setae vary considerably; on the lateral edges of the ventral paratergites their length ranges from $\mathrm{I} 2$ to $38 \mu \mathrm{m}$, and their diameter from 6 to $\mathrm{I} 5 \mu \mathrm{m}$.

Single fringed setae occur on nearly all parts of the ventral surface, but appear to be less common on the prothorax and the medial portions of the abdominal paratergites than on other regions. Large concentrations of them occur along the lateral edges of the third through eighth ventral paratergites. On the second paratergite the leaf-like setae extend all the way to the lateral edge, and there are few fringed setae. On the most posterior segments, however, the extreme lateral portions of the paratergites bear fringed rather than leaflike setae. They occur in largest numbers on the edges of the fifth, sixth, and seventh abdominal segments and become increasingly less numerous on each of the more anterior ones. The eighth paratergite bears fewer of them than the seventh.

In Cryphocricos hungerfordi a narrow strip bearing only plastral hairs separates the leaf-like and fringed setae, and the latter, which occur in a single row, are fewer and farther apart than in C. barozzii. The two types of setae are less clearly separated in $C$. barozzii, whose fringed setae are more numerous, closer together, and in several poorly-defined rows (Fig. I2). Their dense distribution on the lateral edges of the fifth through seventh paratergites in this species suggested, at first, that they might be hydrofuge devices. On the paratergites of $C$. hungerfordi, however, they appear to be too far apart to function in this way. Their sporadic occurrence on nearly all the exposed surfaces of the body suggests that they have some other function, probably a sensory one.

\section{Dorsal Surface}

The dorsal surface of the body was studied only briefly in one specimen of each species of Cryphocricos. In both specimens this surface is covered with considerably more silt and debris than the ventral one. The detritus clings to all the parts of the dorsum which are exposed to the water (Fig. 2, left side); these regions have a roughened appearance under the stereoscopic microscope. 
The surfaces which are concealed by the shortened forewings, however, are relatively free of debris. Except for the third abdominal tergite (Fig. 2, T3) these regions appear smooth under the stereoscopic microscope (Fig. 2, light stippling on right side). The smooth terga and the inner (ventral) surfaces of the forewings lack fringed setae and are covered with densely-packed hydrofuge hairs. Those on the metatergum ( $\mathrm{T}$ III) and second abdominal tergite ( $\mathrm{T}_{2}$ ), which were examined in more detail, possess nodules basally, are at least $5 \mu \mathrm{m}$ long, and have diameters similar to those of the plastral hairs on the ventral surface of the body. The hairs on the inner surface of the forewing are considerably shorter (approximately I.5-2 $\mu \mathrm{m}$ in length) than those on the second abdominal tergite and metatergum. Basal nodules were observed on these alar hairs only in the region of the forewing which is externally visible in ventral view (Fig. I, FW) ; here the hairs are longer, but since their tips appear to coalesce their height could not be estimated.

The surfaces which are exposed to the water are covered with small, wart-like, cuticular protuberances which give them a roughened texture. The raised surfaces of these protuberances, which are approximately $20-35 \mu \mathrm{m}$ in diameter and one to two times this distance apart, lack hairs. Each "wart" bears a small central indentation containing a curious fringed papilla, possibly a sensory device. The large spaces between the protuberances were, unfortunately, covered with debris on all of the exposed abdominal tergites. The anterior third of the third abdominal tergite, however, is overlapped by the posterior edge of the forewing, which largely protects it from debris. In this region, densely-packed hairs, at least $5 \mu \mathrm{m}$ long and 0.3 to $0.4 \mu \mathrm{m}$ wide at the tips, cover the areas between the cuticular "warts". Similar hairs occur between the protuberances on the exposed portion of the mesothoracic tergum (Fig. 2, T II). Quite probably hydrofuge hairs are present between the protuberances on the prothoracic and fourth through seventh abdominal terga, but are hidden beneath the debris. Occasional fringed setae occur on all of the exposed dorsal surfaces of the body, and are especially numerous along the lateral edges of the abdominal terga and in the abdominal intersegmental sulci.

\section{Discussion}

Although in most areas the fringed setae appear to be too widely spaced to retain an air layer, at least two of the other three types of fine structures on the cuticular surface of Cryphocricos appear to be 
plastral devices. The densely-packed hairs on the ventral surfaces of the thorax and abdomen strongly resemble those of Aphelocheirus, which has plastral respiration (Thorpe and Crisp I947a) and differ from those of Pelocoris, which has "air-bubble" respiration (Parsons 1974). The microtrichia in the central portions of the fourth through sixth abdominal sternites have a shingle-like arrangement which strongly resembles that of the plastral devices on the sternites of Torridincola (Coleoptera, Hinton I969b); these microtrichia, along with the hairs between them, probably also retain a thin layer of air.

The function of the leaf-like setae on the paratergites is more problemmatic. They may serve merely to protect the underlying plastral hairs from becoming too clogged with debris to allow the adherent air layer to carry on gas exchange with the water. Although they may, indeed, do this, it is unlikely that it is their sole function, since they are absent in other regions with plastral hairs. In Aphelocheirus, which is also covered with debris, leaf-like setae occur only on the second abdominal sense organs, but the experiments of Thorpe and Crisp (1947a, I947b) have shown that the insect is able to maintain efficient plastral respiration.

The presence of large amounts of air among the elongated leaflike setae on the sense organs of Cryphocricos suggests that the shorter ones on the rest of the paratergites are similarly capable of retaining air, although in smaller and less visible amounts. They may well act in conjunction with the underlying plastral hairs, in much the same way that long and short hydrofuge hairs hold a "macroplastron" external to a "microplastron" in some aquatic Coleoptera such as Hydrophilus piceus (Thorpe and Crisp 1949). Like the long hairs which retain the "macroplastron" in the latter, the leaf-like setae may, under increased hydrostatic pressure, help to protect the thin layer of air, which is trapped in the underlying short hairs, against water entry. When the insect dives to regions of increased pressure the posterolateral slope of the setae may increase, so that the setae become pressed together and form a barrier against water penetration. Their presence only on the paratergites, and their absence in other regions, may be connected with the need to protect the second through eighth abdominal spiracles, which lie on the surfaces of the paratergites, against flooding. The three more anterior pairs of spiracles (mesothoracic, metathoracic, and first abdominal) are concealed within invaginations of the exoskeleton and are thus more protected than the posterior ones against the entry of water. 
Thorpe and Crisp ( $1947 \mathrm{c}$ ) have described how the elongated setae on the abdominal sense organs of Aphelocheirus become compressed under increased pressure, stimulating shorter sensory hairs which are interspersed among them, and thus warning the insect against diving to dangerous depths. The elongated leaf-like setae on the six pairs of abdominal sense organs of Cryphocricos probably have a similar function, and the shorter leaf-like setae on the rest of each paratergite may have evolved from these longer ones.

The efficiency of the plastron in Cryphocricos cannot be determined without experiments similar to those which Thorpe and Crisp ( 1947a, I947b) performed on Aphelocheirus. Nearly all of the ventral surface of Cryphocricos, and at least a part of the exposed dorsal surface, bear apparent hydrofuge devices. If these devices do, indeed, retain a thin, permanent, plastral air layer, a considerable surface area of air is exposed to the water and is capable of gas exchange with the latter. Dissolved oxygen could pass directly to the mesothoracic, metathoracic, and second through eighth abdominal spiracles, all of which face portions of the ventral plastron. Although the dorsal subalar space is not exposed to the water, it communicates with the ventral air layer by means of the narrow gap between the ventrally exposed portion of the forewing (Fig. I, FW) and the ventrolateral edge of the body. The hydrofuge hairs lining this gap would permit a small amount of oxygen to pass from the ventral plastron to the first abdominal spiracle, which faces the subalar space (Parsons 1974). The extent to which the spiracles, especially the first abdominal ones, are capable of inhalation is not known, however, and will require experimentation and further fine-structural studies.

There is a strong possibility that well-developed plastral respiration has evolved in other Naucoridae, as Hinton ( I969a) claims. Further investigation will probably reveal it not only in other members of this family but quite possibly in other families of aquatic Heteroptera as well.

Fig. 11. C. barozzii; shingle-like arrangement of several groups of microtrichia on median portion of fourth abdominal sternite, approximately midway between its anterior (towards top) and posterior (towards bottom) boundaries. Arrow indicates where tips of hairs, mostly concealed by debris, appear to be interspersed among groups of microtrichia. Scale line $=5 \mu \mathrm{m}$.

Fig. 12. C. barozzii; large numbers of fringed setae on lateral edge of sixth ventral abdominal paratergite, left side of body. Arrow indicates edge of body. Scale line $=10 \mu \mathrm{m}$. 


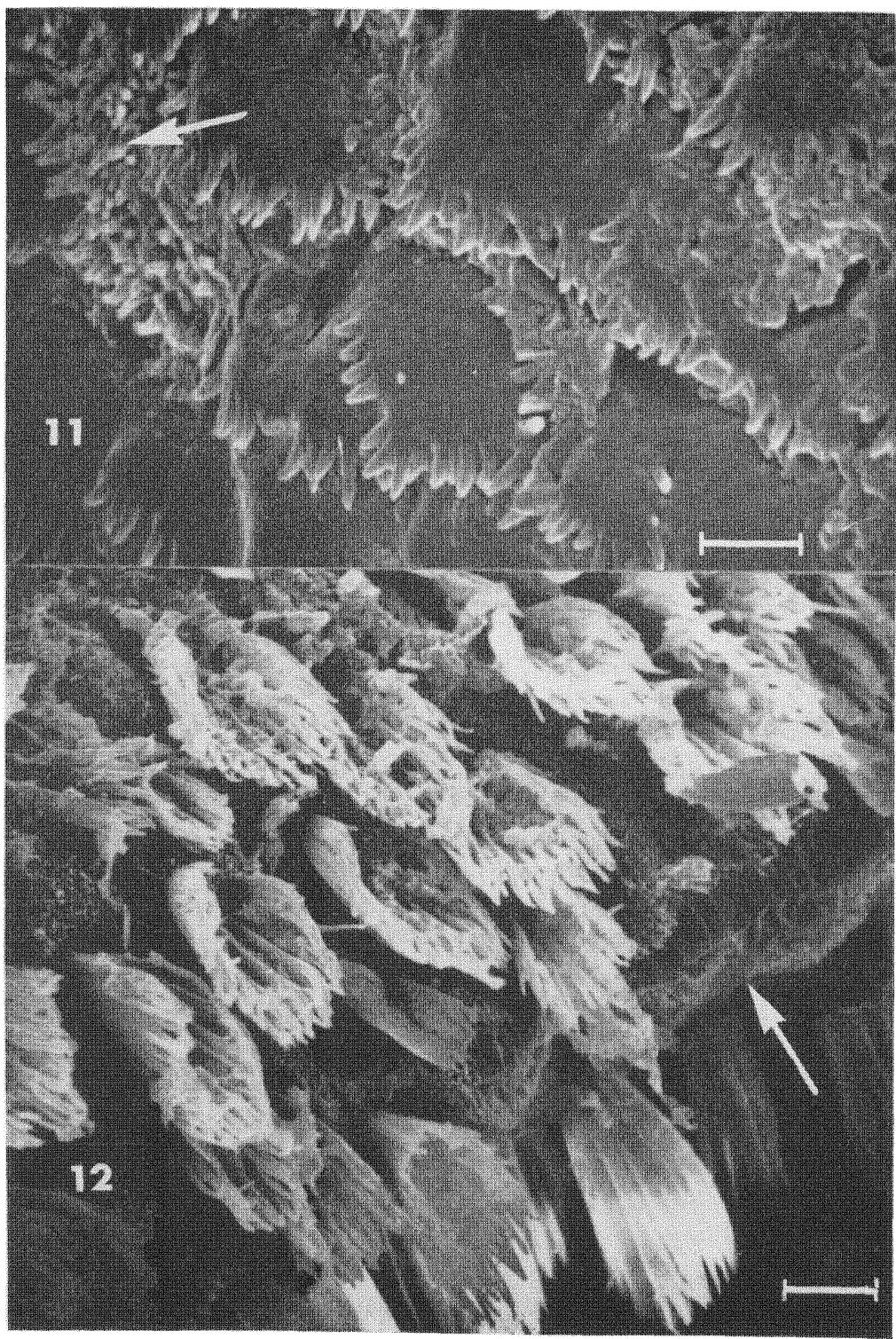




\section{ACKNOWLEDGMENTS}

Acknowledgment is made for the use of the scanning electron microscope in the Royal Ontario Museum, established through a grant from the National Research Council of Canada to the Department of Zoology, University of Toronto. We wish to thank John T. Polhemus, Randall T. Schuh, Fritz Plaumann, and D. T. Crisp, who provided specimens and/or data on habitats. We are also grateful to Eric Lin and Kian Chua for their technical help, to W. H. Thorpe and Thomas S. Parsons for their advice and encouragement, and to Donald A. Chant and the Department of Zoology, University of Toronto, who made available the laboratory facilities for this study. The investigation was made possible by a grant in aid of research to the senior author from the National Research Council of Canada.

\section{Summary}

The scanning electron microscope shows that in Cryphocricos barozzii and $C$. hungerfordi most of the ventral surface of the body and at least a part of the dorsal surface are covered with fine structures which appear to be hydrofuge devices. Both surfaces bear short, fine hairs which are very similar to those of Aphelocheirus aestivalis, the only aquatic heteropteran in which plastral respiration has thus far been demonstrated. These hairs are much smaller and more densely-packed than those of Pelocoris femoratus, which carries a large air bubble and relies upon atmospheric oxygen. On the ventral abdominal paratergites of Cryphocricos the plastral hairs are covered by curious, leaf-like, ridged setae which overlap each other and perhaps retain a "macroplastron". Very elongated leaf-like setae occur on the six pairs of abdominal pressure receptors of Cryphocricos. Aphelocheirus possesses leaf-like setae only on its single pairs of abdominal sense organs. The fourth through sixth abdominal sternites of Cryphocricos bear groups of microtrichia with a shingle-like arrangement; they resemble the plastral devices of some aquatic Coleoptera. These fine structural observations strongly suggest that $C r y$ phocricos has plastral respiration and utilizes dissolved rather than atmospheric oxygen. 


\section{Literature Cited}

Hinton, H. E.

1969a. Algunas pequeńas estructuras de insectos observadas con microscopio electronico explorador. Acta Politecnica Mexicana 10: 181-201.

1969b. Plastron respiration in adult beetles of the suborder MyxoLARSÉN, O. phaga. J. Zool., Lond. 195: 131-137.

1955. Spezifische Mechanorezeptoren bei Aphelocheirus aestivalis Fabr. nebst Bemerkungen über die Respiration dieser Wanze. Lunds Univ. Årsskr. 51(11): 1-58.

Parsons, M. C.

1969. The food pump of Aphelocheirus aestivalis F. as compared with that of typical Naucoridae (Heteroptera). J. Morphol. 129: 1730 .

1974. Anterior displacement of the metathoracic spiracle and lateral intersegmental boundary in the pterothorax of Hydrocorisae

Thorpe, W. H. (aquatic Heteroptera). Z. Morphol. Tiere 79: 165-198.

1950. Plastron respiration in aquatic insects. Biol. Rev. 25: 344-390. Thorpe, W. H. and D. J. Crisp

1947a. Studies on plastron respiration. I. The biology of Aphelocheirus aestivalis [Hemiptera, Aphelocheiridae (Naucoridae)] and the mechanism of plastron retention. J. Exp. Biol. 24: 227-269.

$1947 \mathrm{~b}$. Studies on plastron respiration. II. The respiratory efficiency of the plastron in Aphelocheirus. J. Exp. Biol. 24: 270-303.

$1947 \mathrm{c}$. Studies on plastron respiration. III. The orientation responses of Aphelocheirus [Hemiptera, Aphelocheiridae (Naucoridae)] in relation to plastron respiration; together with an account of specialized pressure receptors in aquatic insects. J. Exp. Biol. 24: 310-328.

1949. Studies on plastron respiration. IV. Plastron respiration in the Coleoptera. J. Exp. Biol. 26: 219-260.

USINGER, R. L.

1956. Aquatic Hemiptera. In Aquatic insects of California. Edited by R. L. Usinger. University of California Press, Berkeley and Los Angeles.

YounG, B.

1944. Respiratory adaptation in an aquatic Hemipteron Cheirochela. Sinensia 15: 141-144. 

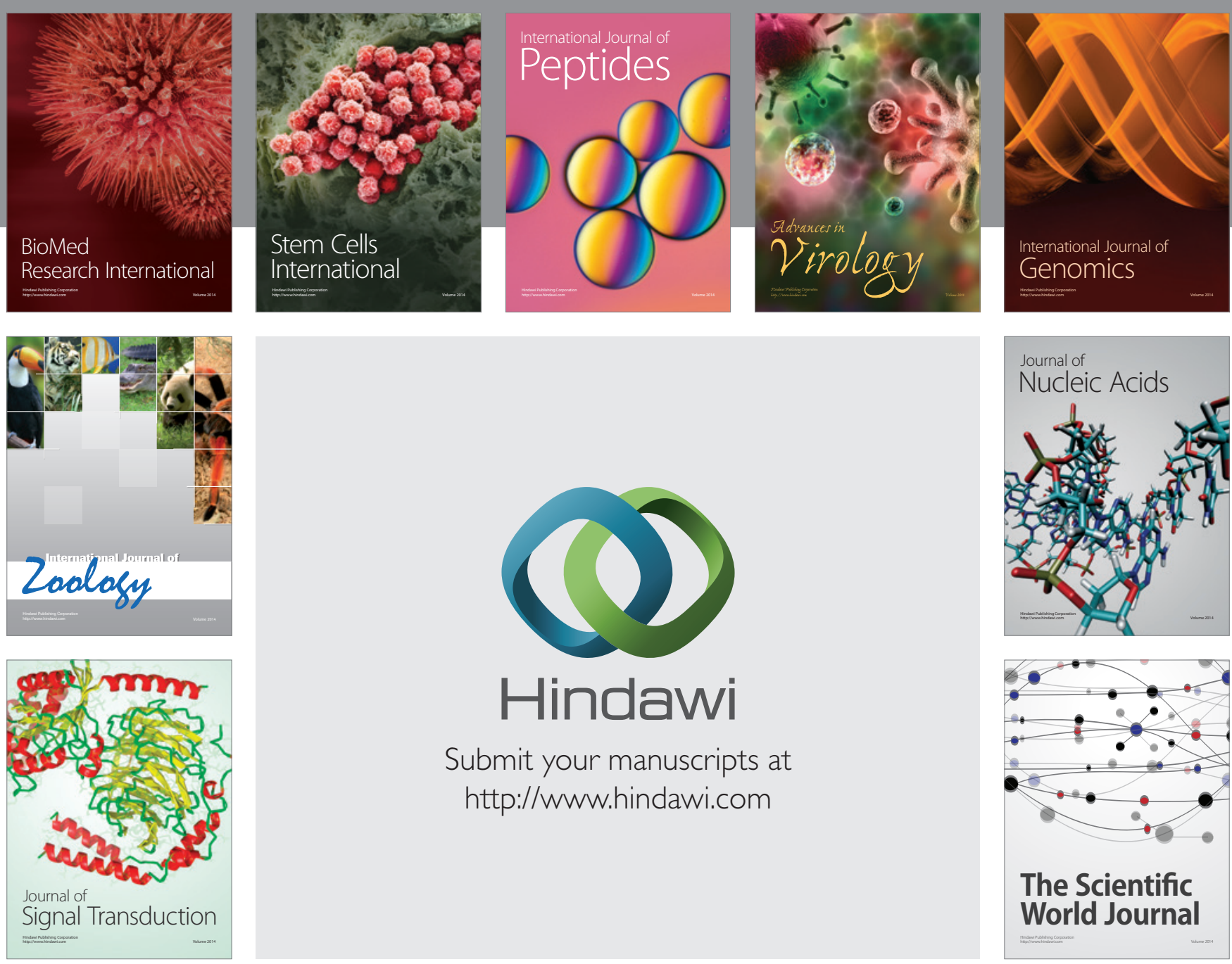

Submit your manuscripts at

http://www.hindawi.com
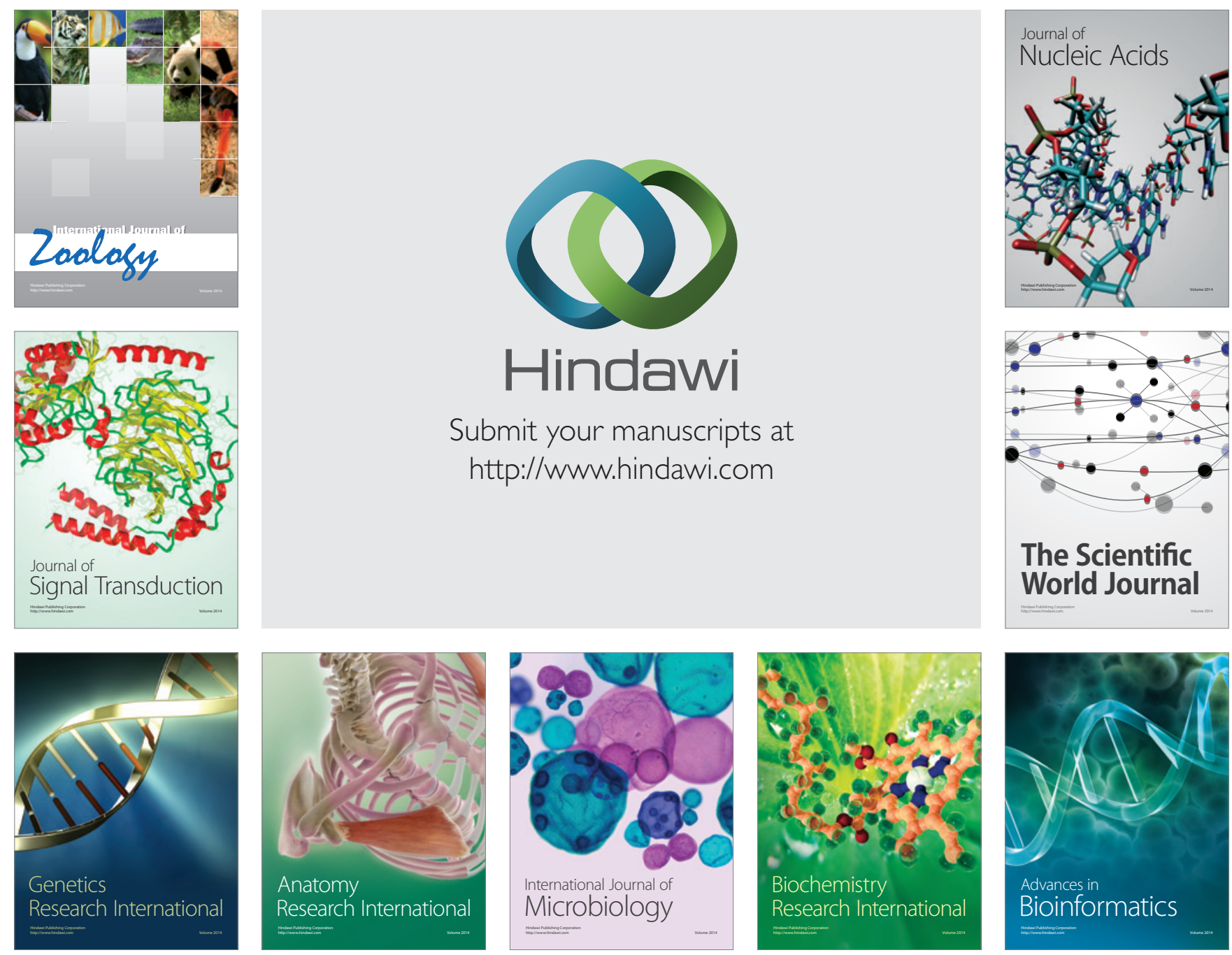

The Scientific World Journal
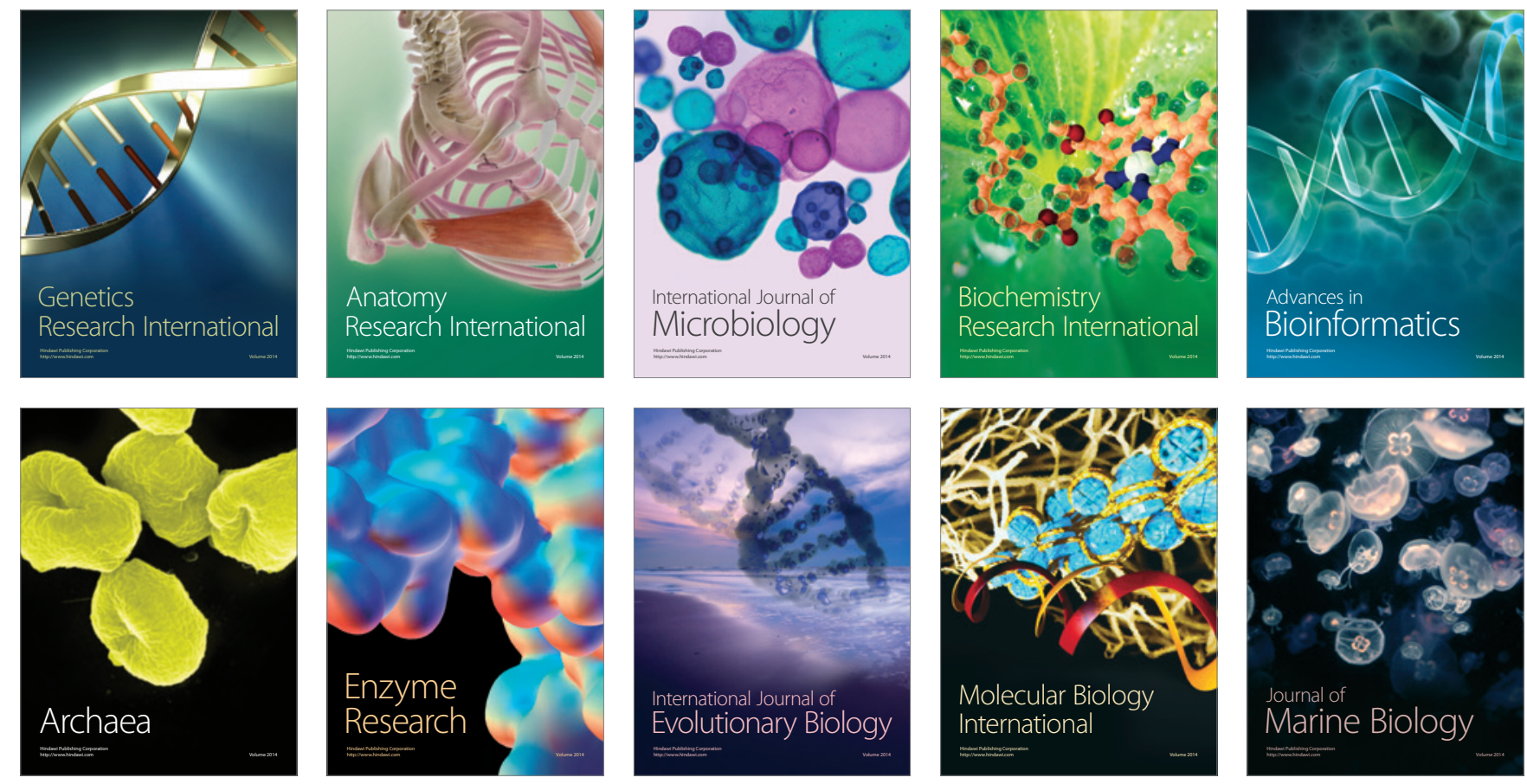